\title{
Modification of Platinum-based Systemic Chemotherapy for Advanced Urothelial Carcinoma in Patients With Suboptimal Renal Function
}

\author{
AKIHIRO HAMADA ${ }^{1}$, TAKESHI SANO ${ }^{1}$, KEIYU MATSUMOTO ${ }^{1,2}$, TORU SAKATANI ${ }^{1}$, \\ KENJI NAKAMURA ${ }^{1}$, ATSURO SAWADA ${ }^{1}$, SHUSUKE AKAMATSU ${ }^{1}$, YOSHIYUKI MATSUI ${ }^{1,3}$, \\ OSAMU OGAWA ${ }^{1,2}$ and TAKASHI KOBAYASHI ${ }^{1}$ \\ ${ }^{1}$ Department of Urology, Kyoto University Graduate School of Medicine, Kyoto, Japan; \\ ${ }^{2}$ Department of Urology, Japanese Red Cross Otsu Hospital, Shiga, Japan; \\ ${ }^{3}$ Department of Urology, National Cancer Center Hospital, Tokyo, Japan
}

\begin{abstract}
Background/Aim: Standard chemotherapy for advanced urothelial carcinoma (UC) patients with moderate renal dysfunction has not yet been established. Patients and Methods: We retrospectively assessed outcomes of patients with advanced UC who underwent first-line chemotherapy with full-/reduced-dose gemcitabine plus cisplatin (GC-f/GC$r$ ) or full-/reduced-dose gemcitabine plus carboplatin $(G-$ Car-f/G-Car-r) according to renal function. Results: Seventyeight patients were included in this study. The objective response rate was $42 \%, 30 \%, 42 \%$, and $27 \%$ for the GC-f, $G C-r$, G-Car-f, and G-Car-r groups, respectively. For the $G C-r$ and G-Car-f groups, the median progression-free survival and the median overall survival was $4.5 \mathrm{vs} .7 .0$ months ( $p=0.07)$ and 7.5 months vs. 12.0 months $(p=0.124)$, respectively. Grade 3/4 thrombocytopenia occurred more frequently in the GC-r group than the G-Car-f group $(80 \%$ vs. 38\%, p=0.021). Conclusion: G-Car-f could be more beneficial than GC-r for patients with advanced UC who have moderate renal dysfunction.
\end{abstract}

Cisplatin-based combination chemotherapy is the standard treatment for patients with unresectable or metastatic urothelial carcinoma (UC) $(1,2)$. However, the prognosis of

This article is freely accessible online.

Correspondence to: Takashi Kobayashi, Department of Urology, Kyoto University Graduate School of Medicine, 54 Shogoin, Kawahara-cho, Sakyo-ku, Kyoto, 606-8507 Japan. Tel: +81 757513337, Fax: +81 757613740, e-mail: selecao@kuhp.kyotou.ac.jp

Key Words: Urothelial carcinoma, chemotherapy, cisplatin, carboplatin, renal dysfunction. these patients remains poor, with a median overall survival (OS) of $12-15$ months $(3,4)$. In addition, more than $50 \%$ of patients with UC are ineligible for optimal doses of cisplatin due to renal dysfunction, poor performance status, advanced age, or comorbidities $(5,6)$. For cisplatin-unfit patients with UC, several studies have demonstrated the efficacy and safety of alternative regimens, such as carboplatin-based regimens $(7,8)$, or reduced-dose cisplatin-based regimens $(9$, 10). However, a consensus for the indication criteria for these regimens based on comparative efficacy and safety data has not yet been reached.

In the present study, we retrospectively analyzed the clinical outcomes of patients who received gemcitabine plus cisplatin (GC) or gemcitabine plus carboplatin (G-Car) as first-line treatment for advanced or metastatic UC patients with moderate renal dysfunction.

\section{Patients and Methods}

Study population. This study included patients with advanced or metastatic UC who underwent first-line chemotherapy with GC or G-Car at our institution between August 2002 and August 2018. The data were retrospectively evaluated. Patients who received these chemotherapies in neoadjuvant or adjuvant settings were excluded. All patients provided written informed consent to participate in this study, and the protocol was approved by the Ethics Committee of Kyoto University Hospital (\#R1581).

Treatments. Patients were stratified according to Cockcroft-Gault creatinine clearance $(\mathrm{CG}-\mathrm{CCr}$ ) values to receive one of four regimens: full-dose GC (GC-f), reduced-dose GC (GC-r), full-dose G-Car (GCar-f), or reduced-dose G-Car (G-Car-r). $\mathrm{CCr}$ ( $\mathrm{ml} / \mathrm{min}$ ) was calculated as: [140-age (years) $\times$ weight $(\mathrm{kg}) \times 1 \quad($ male) or 0.85 (female)]/[72×serum creatinine $(\mathrm{mg} / \mathrm{dl})+0.2](11,12)$. Patients with $\mathrm{CCr} \geq 20-29 \mathrm{ml} / \mathrm{min}$ received G-Car-r; those with $\mathrm{CCr} 30-49 \mathrm{ml} / \mathrm{min}$ received GC-r (including GC split, as described below) or G-Car-f, and those with $\mathrm{CCr} \geq 50 \mathrm{ml} / \mathrm{min}$ received GC-f. Patients with $\mathrm{CCr}<20$ 
$\mathrm{ml} / \mathrm{min}$ were considered to be unfit for chemotherapy and were not included in the study. Several patients received a reduced or modified dose or regimen due to poor performance status or advanced age.

The GC and G-Car regimens were: GC-f: 4-week cycles of $1,000 \mathrm{mg} / \mathrm{m}^{2}$ gemcitabine on days 1,8 , and 15 , and $70 \mathrm{mg} / \mathrm{m}^{2}$ cisplatin on day 2 (1); GC-r: as for GC-f but the cisplatin dose was reduced to $80 \%$; GC split: 3-week cycles of $1,000 \mathrm{mg} / \mathrm{m}^{2}$ gemcitabine on days 1,8 , and 15 , and $35 \mathrm{mg} / \mathrm{m}^{2}$ cisplatin on either days 2 and 3 or days 2 and 9 (9); G-Car-f: 3 -week cycles of 1,000 $\mathrm{mg} / \mathrm{m}^{2}$ gemcitabine on days 1 and 8 , and carboplatin on day 1 at an area under the curve of $4.5(8,13)$; and G-Car-r: as for G-Car-f except for the gemcitabine and carboplatin doses that were reduced to $80 \%$. All chemotherapy regimens continued until disease progression or a severe adverse event (AE) of grade 4 according to the Common Terminology Criteria for Adverse Event (CTCAE) version 4.0. Some patients who experienced moderate AEs (CTCAE grade 3) continued chemotherapy with dose reduction or modification. For statistical evaluation, patients were assigned to the GC-f, GC-r, G-Car-f, or G-Car-r groups according to the dose and regimen of initial chemotherapy.

Assessment of outcomes. Response to treatment was assessed as complete response (CR), partial response (PR), stable disease (SD), or progressive disease (PD) using Response Evaluation Criteria In Solid Tumors (RECIST) version 1.1 (14). The objective response rate (ORR) was defined as the sum of CR and PR rates. Tumor progression was evaluated by computed tomography after every one or two cycles. The grade of hematological and nephrological AEs was evaluated according to CTCAE version 4.0.

Statistical analysis. The primary purpose of the study was to compare efficacy and safety between the GC-r and G-Car-r groups, and the results for patients treated with GC-f and G-Car-r were reviewed for reference. Statistical analyses were performed using JMP ${ }^{\circledR}$ Pro version 15.2 software (SAS Institute, Inc.). Patient characteristics were compared using a Chi-square test and the Mann-Whitney $U$-test. Progression-free survival (PFS) and OS were evaluated using the Kaplan-Meier method with the log-rank test. Changes in blood test results before and after first-line chemotherapy were compared in the GC-r and G-Car-f groups using Wilcoxon's ranked sign test. $p<0.05$ was considered to be statistically significant.

\section{Results}

Patient characteristics. Of the 128 patients who underwent chemotherapy for advanced or metastatic UC at our institution, 78 received platinum-based chemotherapy as first-line treatment and were included in this study. Baseline demographic, clinical, and laboratory characteristics are listed in Table I. The number of patients treated with GC-f, GC-r, G-Car-f, and G-Car-r was 33 (42\%), 10 (including 2 patients treated with GC split) (13\%), 24 (31\%), and 11 (14\%), respectively.

Thirty-four $(43.6 \%)$ patients had primary bladder cancer, of whom $20(59 \%)$ received GC-f. The remaining 44 $(56.4 \%)$ patients had primary urinary upper tract cancer (UTUC), of whom $13(30 \%)$ received GC-f. The lower

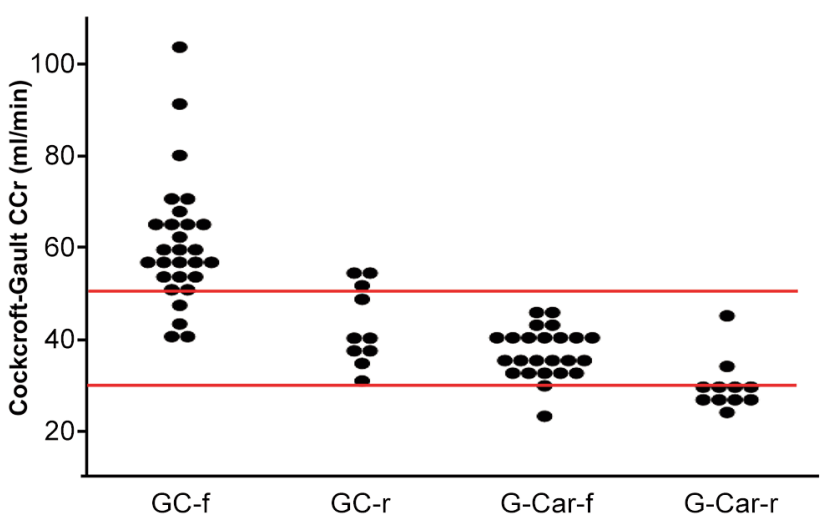

Figure 1. Cockcroft-Gault creatinine clearance (CG-CCr) for patients in the four treatment groups. GC-f: Full-dose gemcitabine plus cisplatin $(n=33)$; GC-r: reduced-dose gemcitabine plus cisplatin ( $n=10)$; G-Car$f$ : full-dose gemcitabine plus carboplatin ( $n=24)$; $G$-Car-r: reduceddose gemcitabine plus carboplatin $(n=11)$. Red lines indicate $C G-C C r$ values of 30 and $50 \mathrm{ml} / \mathrm{min}$.

frequency of GC-f-fit patients for the primary UTUC group compared with the primary bladder cancer group was significant $(p=0.009)$. Comparing the GC-r and G-Car-f groups, there were no differences in gender, age, body mass index, primary tumor site, treatment with radical surgery, Eastern Cooperative Oncology Group Performance Status, or number of metastasis sites. CG-CCr was also not significantly different between the GC-r and the G-Car-f group (Figure 1, Table I). However, the neutrophil to lymphocyte ratio (NLR; $p=0.02$ ), white blood cell (WBC) count ( $p=0.009)$, and C-reactive protein (CRP) concentration $(p=0.008)$ were significantly higher in the GC-r group than the G-Car-f group (Table I).

Efficacy. The median PFS for the GC-f, GC-r, G-Car-f, and G-Car-r groups was 6.0, 4.5, 7.0, and 4.0 months, respectively (Figure 2, left), and the median OS was 14.0, 7.5, 12.0, and 7.0 months, respectively (Figure 2, right). There was no significant difference between the GC-r and G-Car-f groups in either PFS ( $p=0.07)$ or OS ( $p=0.124)$.

The best objective response to first-line chemotherapy for each treatment group is shown in Figure 3. The ORR for GCf, GC-r, G-Car-f, and G-Car-r groups was 42\%, 30\%, 42\%, and $27 \%$ respectively. The PD rate was $50 \%$ for the GC-r group and $25 \%$ for the G-Car-f group ( $p=0.232$, Fisher's exact test).

Dose administration. First-line chemotherapy was discontinued within 1-3 cycles in $42 \%, 60 \%, 42 \%$, and $55 \%$ of patients in the GC-f, GC-r, G-Car-f, and G-Car-r groups, respectively ( $p=0.457$ for GC-r vs. G-Car-f, Fisher's exact test, Figure 4). Notably, $50 \%(n=5)$ of patients in the GC-r group discontinued chemotherapy after the first course due to PD $(n=3)$, nephrotoxicity $(n=1)$, or hepatotoxicity $(n=1)$. 
Table I. Clinical and demographic characteristics of the 78 study patients.

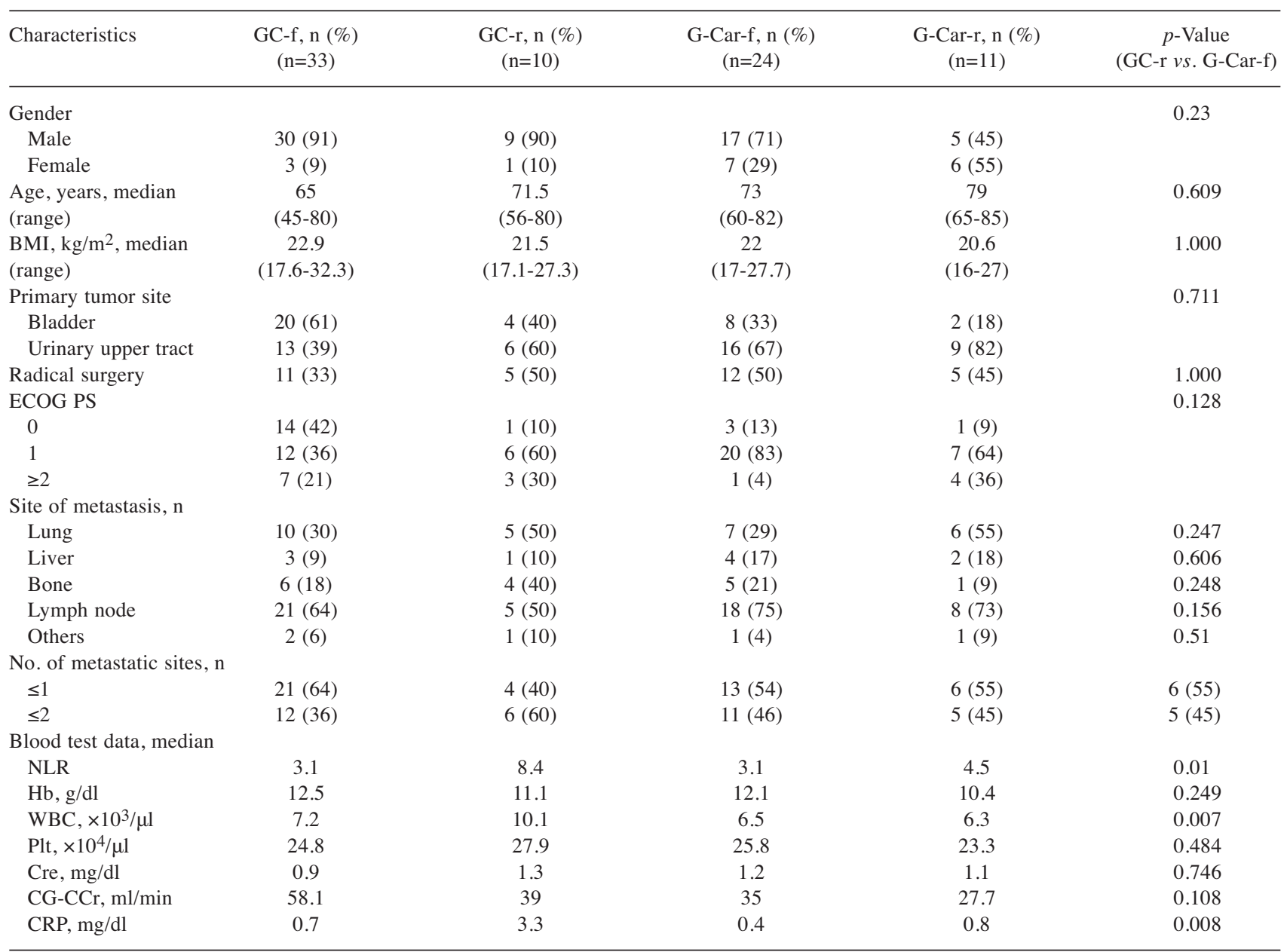

GC-f: Full-dose gemcitabine plus cisplatin; GC-r: reduced-dose gemcitabine plus cisplatin; G-Car-f: full-dose gemcitabine plus carboplatin; G-Carr: reduced-dose gemcitabine plus carboplatin; BMI: body mass index; ECOG PS: Eastern Cooperative Oncology Group Performance Status; NLR: neutrophil to lymphocyte ratio; Hb: hemoglobin; WBC: white blood cell; Plt: platelet; Cre: creatinine; CG-CCr: Cockcroft-Gault creatinine clearance; CRP: C-reactive protein. $p$-Values were determined by the Chi-square test and Mann-Whitney $U$-test.

In total, first-line chemotherapy was discontinued due to AEs in $18 \%, 30 \%, 17 \%$, and $18 \%$ of patients in the GC-f, GC-r, G-Car-f, and G-Car-r groups, respectively ( $p=0.394$ for GCr vs. G-Car-f, Fisher's exact test, Figure 4).

Toxicity. The number of patients who experienced CTCAE grade 3-4 hematologic AEs is shown in Table II. Grade 3-4 thrombocytopenia was significantly more frequent in the GC$r$ group than the G-Car-f group $(80 \% v s .38 \%, p=0.021)$, but no other significant differences in hematologic AEs were detected. Regarding nephrotoxicity, serum creatinine concentrations did not differ before and after first-line chemotherapy for either the GC-r group or G-Car-f group (Figure 5), although one patient developed acute kidney injury after the first course of GC-r, leading to discontinuation of the chemotherapy. All five patients in the GC-r group who discontinued chemotherapy after the first cycle had relatively high pretreatment serum creatinine concentrations (Figure 5).

Other measures. Because we previously reported that NLR is a prognostic factor for subsequent pembrolizumab treatment after first-line chemotherapy in UC patients (15), we also evaluated NLR in the present study. As shown in Figure 6, we detected no significant changes in NLR in the GC-r group ( $p=0.695)$ or G-Car-f group $(p=1.000)$.

\section{Discussion}

Cisplatin-based chemotherapy is the gold standard in the first-line treatment of patients with advanced or metastatic 


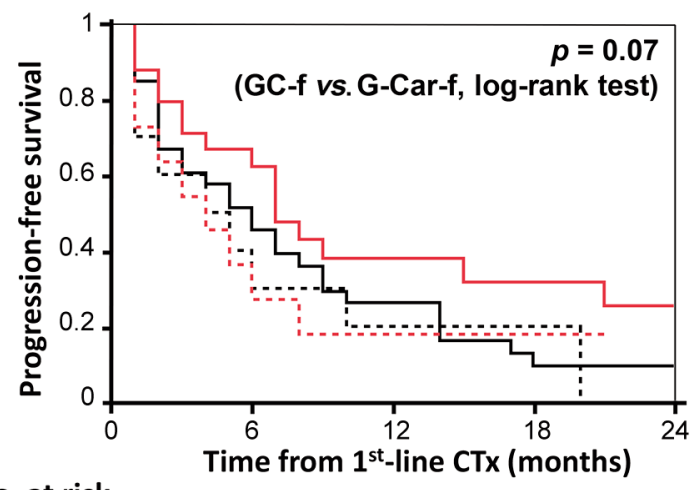

No. at risk

\begin{tabular}{lrrrrl}
\hline GC-f & 33 & 17 & 9 & 4 & 4 \\
GC-r & 10 & 4 & 3 & 3 & 2 \\
G-Car-f & 24 & 25 & 7 & 6 & 5 \\
G-Car-r & 11 & 4 & 3 & 2 & 1 \\
\hline
\end{tabular}

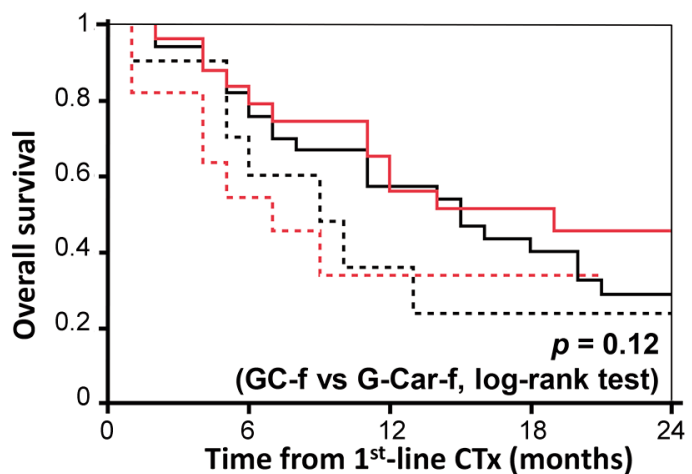

No. at risk

\begin{tabular}{lrrrrl}
\hline GC-f & 33 & 27 & 21 & 12 & 9 \\
GC-r & 10 & 7 & 4 & 3 & 3 \\
G-Car-f & 24 & 19 & 14 & 11 & 8 \\
G-Car-r & 11 & 7 & 3 & 2 & 1 \\
\hline
\end{tabular}

\section{GC-f}

GC-r

G-Car-f

\section{G-Car-r}

Figure 2. Kaplan-Meier curves for progression-free survival (PFS, left) and overall survival (OS, right) of patients in the four treatment groups. GC-f: Full-dose gemcitabine plus cisplatin; GC-r: reduced-dose gemcitabine plus cisplatin; G-Car-f: full-dose gemcitabine plus carboplatin; GCar-r: reduced-dose gemcitabine plus carboplatin; Ctx: chemotherapy.

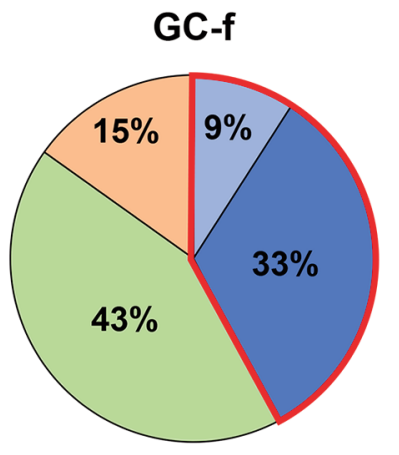

G-Car-f

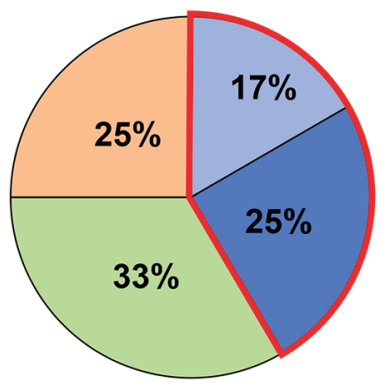

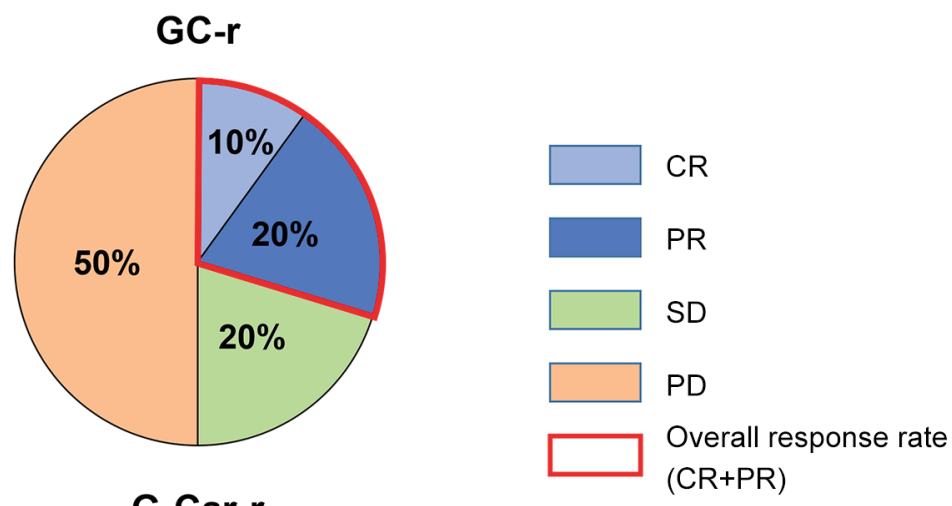

G-Car-r

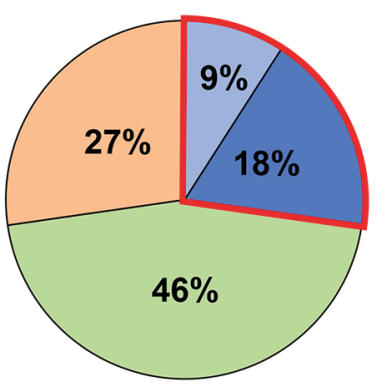

Figure 3. Best objective responses in tumor size for patients in the four treatment groups. GC-f: Full-dose gemcitabine plus cisplatin (n=33); GC$r$ : reduced-dose gemcitabine plus cisplatin (n=10); G-Car-f: full-dose gemcitabine plus carboplatin (n=24); G-Car-r: reduced-dose gemcitabine plus carboplatin (n=11); CR: complete response; PR: partial response; SD: stable disease; PD: progressive disease. 
$(\%)$

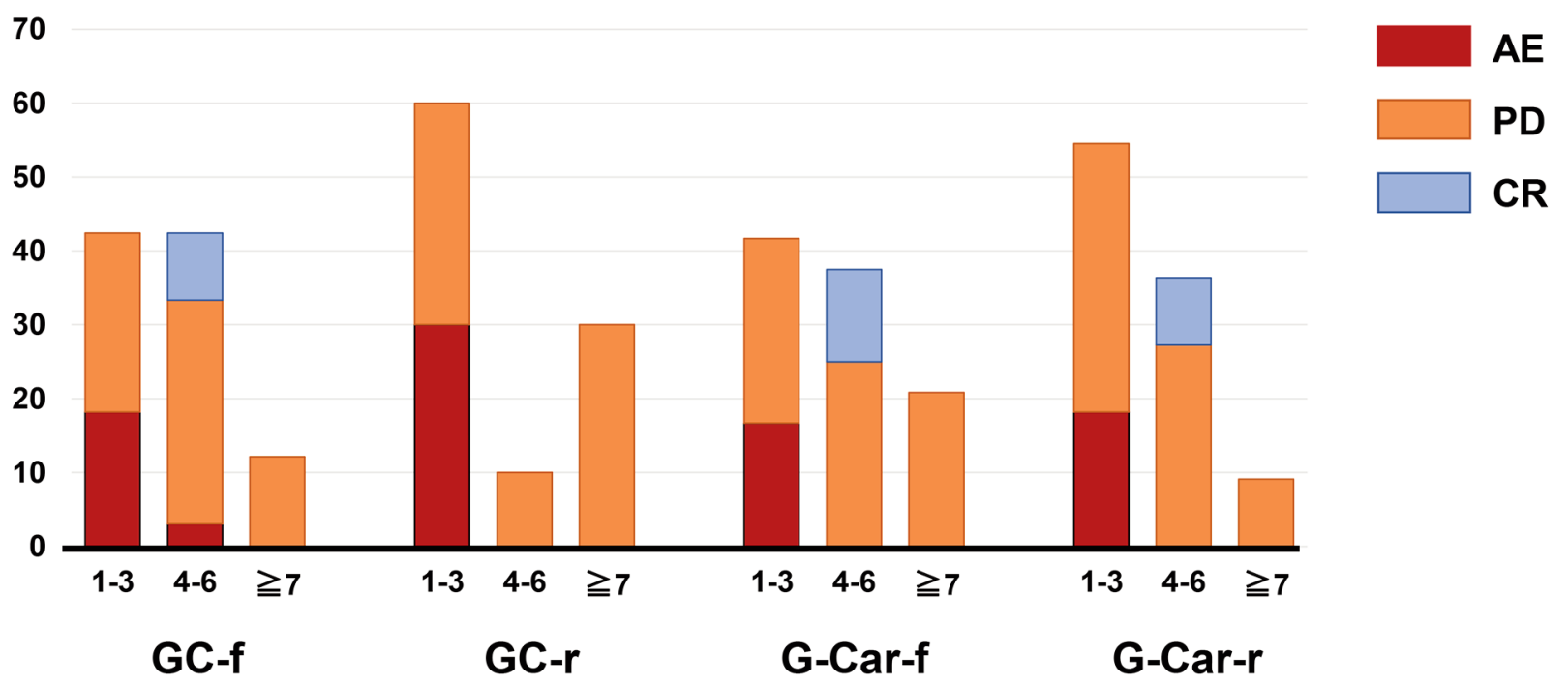

Figure 4. Cycles of treatment completed before discontinuation for the four treatment groups. GC-f: Full-dose gemcitabine plus cisplatin (n=33); GC-r: reduced-dose gemcitabine plus cisplatin ( $n=10)$; G-Car-f: full-dose gemcitabine plus carboplatin (n=24); G-Car-r: reduced-dose gemcitabine plus carboplatin ( $n=11) ; A E$ : adverse event; $C R$ : complete response; PD: progressive disease.

Table II. Grade 3-4 hematologic adverse events.

\begin{tabular}{lccccc}
\hline Characteristics & $\begin{array}{c}\text { GC-f, } \mathrm{n}(\%) \\
(\mathrm{n}=33)\end{array}$ & $\begin{array}{c}\text { GC-r, } \mathrm{n}(\%) \\
(\mathrm{n}=10)\end{array}$ & $\begin{array}{c}\text { G-Car-f, } \mathrm{n}(\%) \\
(\mathrm{n}=24)\end{array}$ & $\begin{array}{c}\text { G-Car-r, } \mathrm{n}(\%) \\
(\mathrm{n}=11)\end{array}$ & $\begin{array}{c}p \text {-Value } \\
(\mathrm{GC}-\mathrm{r} v s . \mathrm{G}-\mathrm{Car}-\mathrm{f})\end{array}$ \\
\hline Leukopenia & $3(9)$ & $4(40)$ & $8(33)$ & $2(18)$ & 0.712 \\
Neutropenia & $13(39)$ & $5(50)$ & $9(38)$ & $3(27)$ & 0.502 \\
Thrombocytopenia & $10(30)$ & $3(80)$ & $7(29)$ & $4(36)$ & 0.021 \\
Anemia & $5(15)$ & $3(30)$ & $5(45)$ & 0.961 \\
\hline
\end{tabular}

GC-f: Full-dose gemcitabine plus cisplatin; GC-r: reduced-dose gemcitabine plus cisplatin; G-Car-f: full-dose gemcitabine plus carboplatin; G-Carr: reduced-dose gemcitabine plus carboplatin. $p$-Values were determined by the Chi-square test.

UC. However, a large proportion of patients are ineligible for cisplatin therapy due to renal dysfunction, age, poor performance status, or comorbidities affecting other organs (16). In the present study, $58 \%$ of the 78 patients were ineligible for full-dose cisplatin according to our indication criteria. The proportion of cisplatin-unfit patients was larger for patients with primary UTUC than for patients with primary bladder cancer, probably due to greater renal impairment.

The proportion of patients ineligible for full-dose cisplatin in the present study is higher than the corresponding rate of $28 \%$ observed in a previous study of UC patients (17). This difference is likely to be due, at least in part, to the older age of our patients; indeed, this would be consistent with the finding by Dash et al. (17) that more than $40 \%$ of their elderly patients (aged $>70$ years) were ineligible for full-dose cisplatin treatment.
Our strategy of allocating chemotherapy regimens according to CG-CCr was partially based on the Galsky criteria for selecting patients eligible for cisplatin-based chemotherapy (5). Although the Galsky criteria defines patients with CG-CCr $<60 \mathrm{ml} / \mathrm{min}$ as unfit for cisplatin therapy, we administered full-dose GC to patients with CG$\mathrm{CCr} 50-60 \mathrm{ml} / \mathrm{min}$ and found that it was efficacious and safe. Patients with CG-CCr $<50 \mathrm{ml} / \mathrm{min}$ who were treated with GCar-f showed better ORR, PFS, and OS than those treated with GC-r. Our results are consistent with the results of previous studies reporting an ORR of $36.0-60.8 \%$ and median OS of 7.2-15.4 months for UC patients treated with $\mathrm{G}-\mathrm{Car}(7,8,13,18-20)$.

We found that treatment discontinuation within 3 cycles and grade 3/4 hematological toxicity were most common among patients in the GC-r group. In particular, 50\% ( $\mathrm{n}=5)$ of the patients in the GC-r group discontinued treatment after 
2.5

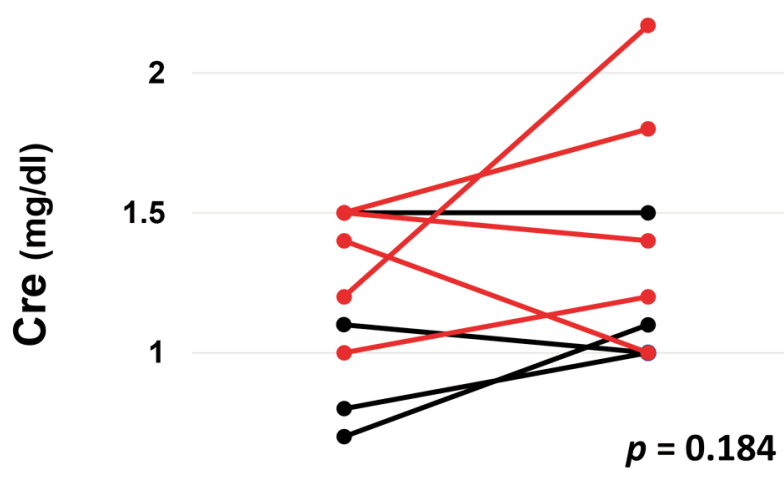

0.5

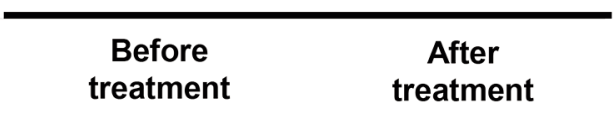

GC-r
2.5

2

1.5

1

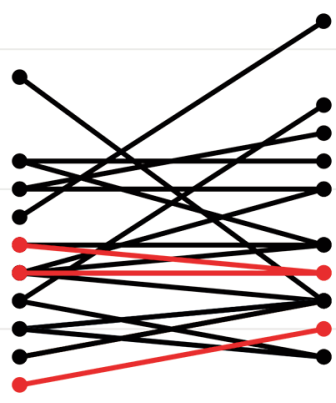

$p=0.215$
0

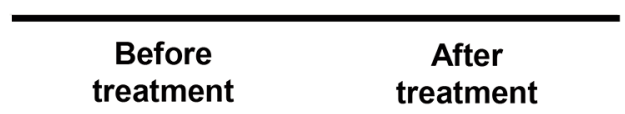

G-Car-f

Figure 5. Serum creatinine (Cre) concentrations before and after first-line chemotherapy for patients treated with reduced-dose gemcitabine plus cisplatin $(G C-r, n=10)$ or full-dose gemcitabine plus carboplatin $(G$-Car-f, $n=24)$. Patients who discontinued the regimen after the first cycle are shown in red.p-Values were determined by the Wilcoxon ranked sign test.

25

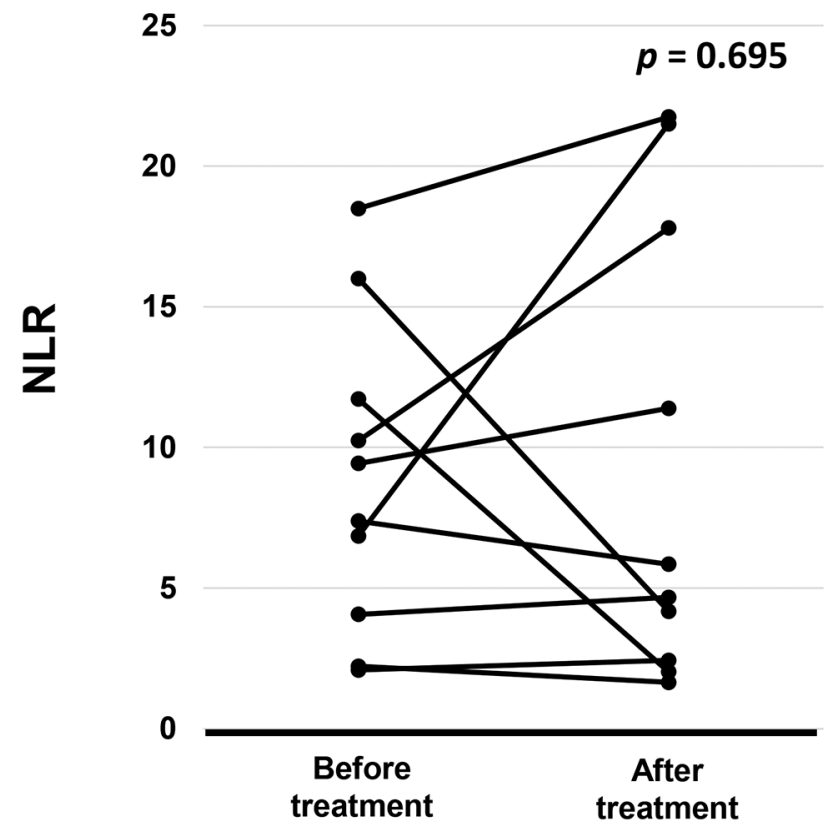

GC-r
25

$$
p=1.00
$$

20

15

10

5

0

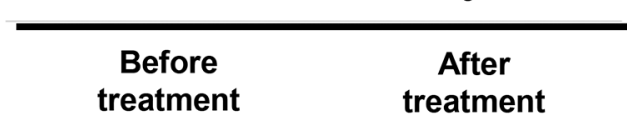

G-Car-f

Figure 6. Neutrophil to lymphocyte ratio (NLR) before and after first-line chemotherapy for patients treated with reduced-dose gemcitabine plus cisplatin $(G C-r, n=10)$ or full-dose gemcitabine plus carboplatin $(G$-Car-f, $n=24)$. p-Values were determined by the Wilcoxon ranked sign test. 
the first cycle. These findings suggest that the dose intensity of G-Car-f, which was based on CG-CCr according to the Calvert formula, was associated with a more favorable safety profile compared with the fixed dose based on body surface area in GC-r.

Two earlier studies compared G-Car with GC split for UC patients with marginally impaired renal function, and reported more favorable response and tolerability of GC split compared with G-Car $(21,22)$. However, these studies were inconclusive due to the small sample sizes. In the present study, G-Car-f gave results comparable to GC-f, but G-Carf may be more beneficial than GC-r to patients with $\mathrm{CCr}<50$ $\mathrm{ml} / \mathrm{min}$ in terms of both efficacy and safety. This discrepancy between the previous studies and ours may be attributed to differences in patient clinicopathological characteristics, including renal function and treatment indication. Further data must be obtained before a final consensus can be reached on the optimal treatment regimen for UC patients with marginal renal dysfunction.

Immune checkpoint inhibitors have improved the survival of patients with advanced UC $(23,24)$. Although cisplatinbased chemotherapy is still recommended for cisplatineligible patients, atezolizumab and pembrolizumab, which target the PD-L1-PD-1 checkpoint, are recommended as first-line therapy options for patients with locally advanced or metastatic disease who are not eligible for cisplatincontaining chemotherapy and whose tumors express PD-L1, or in patients who are not eligible for any platinumcontaining chemotherapy regardless of PD-L1 expression (25). However, only $20-30 \%$ of patients with advanced UC exhibit PD-L1 overexpression $(26,27)$ and the use of immune checkpoint inhibitors as first-line treatment has not yet been approved in Japan. Therefore, platinum-based chemotherapy still represents the backbone of first-line treatment for a majority of patients, and there remains a strong need to determine the optimal regimen or dose control for cisplatin-ineligible patients with renal dysfunction.

NLR and hemoglobin ( $\mathrm{Hb})$ concentrations have been reported to be associated with oncological outcomes of UC patients receiving second-line pembrolizumab (15). In the present study, however, we detected no significant changes in NLR or $\mathrm{Hb}$ (data not shown) before and after first-line chemotherapy for patients treated with GC-r or G-Car-f.

There are several limitations to this study. The patient number was small and they were selected from a single institution. Although we excluded patients who received chemotherapies in neoadjuvant or adjuvant settings, perioperative chemotherapy may have influenced the AE findings to some extent. In addition, the baseline characteristics of patients in the four groups were not distributed evenly because of the retrospective nature of the study. In particular, NLR, WBC, and CRP were significantly higher in the GC-r group than the G-Car-f group, suggesting that patients in the GC-r group may have had a more aggressive advanced UC. Randomized studies with larger populations may be required to confirm our observations. It is unclear whether our results can be applicable to UC patients receiving other chemotherapeutic regimens $(28,29)$.

In conclusion, our data suggest that G-Car-f may be more beneficial than GC-r for patients with advanced or metastatic UC who have moderate renal dysfunction. Additional data will be needed to confirm the optimal indication criteria for cisplatin-ineligible patients.

\section{Conflicts of Interest}

The Authors have no conflicts of interest to declare in relation to this study.

\section{Author's Contributions}

All Authors of this research paper have directly participated in the planning, execution, or analysis of the study. All Authors of this paper have read and approved the final version submitted.

\section{Acknowledgements}

This study was supported in part by Grants-in-aid from the Ministry of Education and Science to T.K. (\# 25713055 and \# 19H03790) and O.O. (\# 26253078). The Authors thank Anne M. O'Rourke, Ph.D. from Edanz Group (https://en-author-services.edanz.com/ac) for editing a draft of this manuscript.

\section{References}

1 von der Maase H, Sengelov L, Roberts JT, Ricci S, Dogliotti L, Oliver T, Moore MJ, Zimmermann A and Arning M: Long-term survival results of a randomized trial comparing gemcitabine plus cisplatin, with methotrexate, vinblastine, doxorubicin, plus cisplatin in patients with bladder cancer. J Clin Oncol 23(21): 4602-4608, 2005. PMID: 16034041. DOI: 10.1200/JCO. 2005.07.757

2 Sternberg CN, de Mulder P, Schornagel JH, Theodore C, Fossa $\mathrm{SD}$, van Oosterom AT, Witjes JA, Spina M, van Groeningen CJ, Duclos B, Roberts JT, de Balincourt C, Collette L and EORTC Genito-Urinary Cancer Group: Seven year update of an EORTC phase III trial of high-dose intensity M-VAC chemotherapy and G-CSF versus classic M-VAC in advanced urothelial tract tumours. Eur J Cancer 42(1): 50-54, 2006. PMID: 16330205. DOI: $10.1016 /$ j.ejca.2005.08.032

3 Necchi A, Pond GR, Raggi D, Giannatempo P, Vogelzang NJ, Grivas P, Galsky MD, Bellmunt J and Sonpavde G: Efficacy and safety of gemcitabine plus either taxane or carboplatin in the first-line setting of metastatic urothelial carcinoma: a systematic review and meta-analysis. Clin Genitourin Cancer 15(1): 2330.e2, 2017. PMID: 27324051. DOI: 10.1016/j.clgc.2016.05.003

4 Sridhar SS: Evolving treatment of advanced urothelial cancer. J Oncol Pract 13(5): 309-315, 2017. PMID: 28489981. DOI: 10.1200/JOP.2017.022137

5 Galsky MD, Hahn NM, Rosenberg J, Sonpavde G, Hutson T, Oh WK, Dreicer R, Vogelzang N, Sternberg CN, Bajorin DF and 
Bellmunt J: Treatment of patients with metastatic urothelial cancer "unfit" for Cisplatin-based chemotherapy. J Clin Oncol 29(17): 2432-2438, 2011. PMID: 21555688. DOI: 10.1200/ JCO.2011.34.8433

6 Vaughn DJ: Chemotherapeutic options for cisplatin-ineligible patients with advanced carcinoma of the urothelium. Cancer Treat Rev 34(4): 328-338, 2008. PMID: 18262363. DOI: 10.1016/j.ctrv.2007.12.006

7 Dogliotti L, Cartenì G, Siena S, Bertetto O, Martoni A, Bono A Amadori D, Onat $\mathrm{H}$ and Marini L: Gemcitabine plus cisplatin versus gemcitabine plus carboplatin as first-line chemotherapy in advanced transitional cell carcinoma of the urothelium: results of a randomized phase 2 trial. Eur Urol 52(1): 134-141, 2007. PMID: 17207911. DOI: 10.1016/j.eururo.2006.12.029

8 De Santis M, Bellmunt J, Mead G, Kerst JM, Leahy M, Maroto P, Gil T, Marreaud S, Daugaard G, Skoneczna I, Collette S, Lorent J, de Wit R and Sylvester R: Randomized phase II/III trial assessing gemcitabine/carboplatin and methotrexate/ carboplatin/vinblastine in patients with advanced urothelial cancer who are unfit for cisplatin-based chemotherapy: EORTC study 30986. J Clin Oncol 30(2): 191-199, 2012. PMID: 22162575. DOI: $10.1200 / \mathrm{JCO} .2011 .37 .3571$

9 Hussain SA, Stocken DD, Riley P, Palmer DH, Peake DR, Geh JI, Spooner D and James ND: A phase I/II study of gemcitabine and fractionated cisplatin in an outpatient setting using a 21-day schedule in patients with advanced and metastatic bladder cancer. Br J Cancer 91(5): 844-849, 2004. PMID: 15292922. DOI: $10.1038 /$ sj.bjc.6602112

10 Carles J, Suárez C, Mesía C, Nogué M, Font A, Doménech M, Suárez M, Tusquets I, Gallén M, Albanell J and Fabregat X: Feasiblity study of gemcitabine and cisplatin administered every two weeks in patients with advanced urothelial tumors and impaired renal function. Clin Transl Oncol 8(10): 755-757, 2006. PMID: 17074675. DOI: 10.1007/s12094-006-0123-8

11 Cockcroft DW and Gault MH: Prediction of creatinine clearance from serum creatinine. Nephron 16(1): 31-41, 1976. PMID: 1244564. DOI: 10.1159/000180580

12 Ando M, Minami H, Ando Y, Saka H, Sakai S, Yamamoto M, Sasaki Y, Shimokata K and Hasegawa Y: Multi-institutional validation study of carboplatin dosing formula using adjusted serum creatinine level. Clin Cancer Res 6(12): 4733-4738, 2000. PMID: 11156227.

13 Bellmunt J, de Wit R, Albanell J and Baselga J: A feasibility study of carboplatin with fixed dose of gemcitabine in "unfit" patients with advanced bladder cancer. Eur J Cancer 37(17): 2212-2215, 2001. PMID: 11677109. DOI: 10.1016/s09598049(01)00295-7

14 Eisenhauer EA, Therasse P, Bogaerts J, Schwartz LH, Sargent D, Ford R, Dancey J, Arbuck S, Gwyther S, Mooney M, Rubinstein L, Shankar L, Dodd L, Kaplan R, Lacombe D and Verweij J: New response evaluation criteria in solid tumours: revised RECIST guideline (version 1.1). Eur J Cancer 45(2): 228-247, 2009. PMID: 19097774. DOI: 10.1016/j.ejca. 2008.10.026

15 Kobayashi T, Ito K, Kojima T, Kato M, Kanda S, Hatakeyama S, Matsui Y, Matsushita Y, Naito S, Shiga M, Miyake M, Muro Y, Nakanishi S, Kato Y, Shibuya T, Hayashi T, Yasumoto H, Yoshida T, Uemura M, Taoka R, Kamiyama M, Ogawa O, Kitamura H, Nishiyama $\mathrm{H}$ and Japan Urological Oncology Group: Risk stratification for the prognosis of patients with chemoresistant urothelial cancer treated with pembrolizumab. Cancer Sci 112(2): 760-773, 2021. PMID: 33283385. DOI: $10.1111 /$ cas.14762

16 Bellmunt J, Mottet N and De Santis M: Urothelial carcinoma management in elderly or unfit patients. EJC Suppl 14(1): 1-20, 2016. PMID: 27358584. DOI: 10.1016/j.ejcsup.2016.01.001

17 Dash A, Galsky MD, Vickers AJ, Serio AM, Koppie TM, Dalbagni G and Bochner BH: Impact of renal impairment on eligibility for adjuvant cisplatin-based chemotherapy in patients with urothelial carcinoma of the bladder. Cancer 107(3): 506513, 2006. PMID: 16773629. DOI: 10.1002/cncr.22031

18 Hoschke B, May M, Seehafer M and Helke C: Our experience with 23 consecutive patients on gemcitabine/carboplatin chemotherapy for treatment of metastasized transitional cell carcinoma of the urothelium. Int J Urol 11(7): 461-466, 2004. PMID: 15242353. DOI: 10.1111/j.0919-8172.2004.00846.x

19 Linardou H, Aravantinos G, Efstathiou E, Kalofonos C, Anagnostopoulos A, Deliveliotis C, Bafaloukos D, Athanasios Dimopoulos M, Bamias A and Phase II study of Hellenic Cooperative Oncology Group: Gemcitabine and carboplatin combination as first-line treatment in elderly patients and those unfit for cisplatin-based chemotherapy with advanced bladder carcinoma: Phase II study of the Hellenic Co-operative Oncology Group. Urology 64(3): 479-484, 2004. PMID: 15351574. DOI: 10.1016/j.urology.2004.04.024

20 Park I, Kim BS, Lim HY, Kim HJ, Lee HJ, Choi YJ, Park KH, Lee $\mathrm{KH}$, Yoon S, Hong B, Hong JH, Ahn $\mathrm{H}$ and Lee JL: Gemcitabine plus carboplatin versus gemcitabine plus oxaliplatin in cisplatin-unfit patients with advanced urothelial carcinoma: a randomised phase II study (COACH, KCSG GU10-16). Eur J Cancer 127: 183-190, 2020. PMID: 31668839. DOI: 10.1016/ j.ejca.2019.08.034

21 Izumi K, Iwamoto H, Yaegashi H, Shigehara K, Nohara T, Kadono Y and Mizokami A: Gemcitabine plus cisplatin split versus gemcitabine plus carboplatin for advanced urothelial cancer with cisplatin-unfit renal function. In Vivo 33(1): 167172, 2019. PMID: 30587618. DOI: 10.21873/invivo.11454

22 Kim YR, Lee JL, You D, Jeong IG, Song C, Hong B, Hong JH and Ahn H: Gemcitabine plus split-dose cisplatin could be a promising alternative to gemcitabine plus carboplatin for cisplatin-unfit patients with advanced urothelial carcinoma. Cancer Chemother Pharmacol 76(1): 141-153, 2015. PMID: 26001531. DOI: $10.1007 / \mathrm{s} 00280-015-2774-\mathrm{Z}$

23 Bellmunt J, de Wit R, Vaughn DJ, Fradet Y, Lee JL, Fong L, Vogelzang NJ, Climent MA, Petrylak DP, Choueiri TK, Necchi A, Gerritsen W, Gurney H, Quinn DI, Culine S, Sternberg CN, Mai Y, Poehlein CH, Perini RF, Bajorin DF and KEYNOTE-045 Investigators: Pembrolizumab as second-line therapy for advanced urothelial carcinoma. N Engl J Med 376(11): 10151026, 2017. PMID: 28212060. DOI: 10.1056/NEJMoa1613683

24 Powles T, Park SH, Voog E, Caserta C, Valderrama BP, Gurney H, Kalofonos H, Radulović S, Demey W, Ullén A, Loriot Y, Sridhar SS, Tsuchiya N, Kopyltsov E, Sternberg CN, Bellmunt J, Aragon-Ching JB, Petrylak DP, Laliberte R, Wang J, Huang B, Davis C, Fowst C, Costa N, Blake-Haskins JA, di Pietro A and Grivas P: Avelumab maintenance therapy for advanced or metastatic urothelial carcinoma. N Engl J Med 383(13): 12181230, 2020. PMID: 32945632. DOI: 10.1056/NEJMoa2002788

25 Flaig TW, Spiess PE, Agarwal N, Bangs R, Boorjian SA, Buyyounouski MK, Chang S, Downs TM, Efstathiou JA, 
Friedlander T, Greenberg RE, Guru KA, Guzzo T, Herr HW, Hoffman-Censits J, Hoimes C, Inman BA, Jimbo M, Kader AK, Lele SM, Michalski J, Montgomery JS, Nandagopal L, Pagliaro LC, Pal SK, Patterson A, Plimack ER, Pohar KS, Preston MA, Sexton WJ, Siefker-Radtke AO, Tward J, Wright JL, Gurski LA and Johnson-Chilla A: Bladder Cancer, Version 3.2020, NCCN Clinical Practice Guidelines in Oncology. J Natl Compr Canc Netw 18(3): 329-354, 2020. PMID: 32135513. DOI: 10.6004/ jnccn.2020.0011

26 Balar AV, Galsky MD, Rosenberg JE, Powles T, Petrylak DP, Bellmunt J, Loriot Y, Necchi A, Hoffman-Censits J, PerezGracia JL, Dawson NA, van der Heijden MS, Dreicer R, Srinivas S, Retz MM, Joseph RW, Drakaki A, Vaishampayan UN, Sridhar SS, Quinn DI, Durán I, Shaffer DR, Eigl BJ, Grivas PD, Yu EY, Li S, Kadel EE 3rd, Boyd Z, Bourgon R, Hegde PS, Mariathasan S, Thåström A, Abidoye $\mathrm{OO}$, Fine GD, Bajorin DF and IMvigor210 Study Group: Atezolizumab as first-line treatment in cisplatin-ineligible patients with locally advanced and metastatic urothelial carcinoma: a single-arm, multicentre, phase 2 trial. Lancet 389(10064): 67-76, 2017. PMID: 27939400. DOI: 10.1016/S0140-6736(16)32455-2

27 Vuky J, Balar AV, Castellano D, O’Donnell PH, Grivas P, Bellmunt J, Powles T, Bajorin D, Hahn NM, Savage MJ, Fang X, Godwin JL, Frenkl TL, Homet Moreno B, de Wit R and Plimack ER: Long-term outcomes in KEYNOTE-052: Phase II study investigating first-line pembrolizumab in cisplatinineligible patients with locally advanced or metastatic urothelial cancer. J Clin Oncol 38(23): 2658-2666, 2020. PMID: 32552471. DOI: $10.1200 /$ JCO.19.01213
28 Ogawa M, Yamamoto S, Inoue T, Numao N, Yuasa T, Masuda H, Fukui I and Yonese J: Phase II study of second-line chemotherapy with paclitaxel, gemcitabine, and cisplatin for advanced urothelial carcinoma. Anticancer Res 40(3): 16131618, 2020. PMID: 32132064. DOI: 10.21873/anticanres.14109

29 Hung SC, Wang SS, Yang CK, Li JR, Cheng CL, Ou YC, Ho $\mathrm{HC}$, Chiu KY and Chen CS: Comparison of efficacy of adjuvant MEC (methotrexate, epirubicin and cisplatin) and GC (gemcitabine and cisplatin) in advanced upper tract urothelial carcinoma. Anticancer Res 37(4): 1875-1883, 2017. PMID: 28373455. DOI: 10.21873/anticanres.11525
Received June 30, 2021

Revised July 11, 2021

Accepted July 12, 2021 